\title{
Extrato de Corymbia citriodora sobre a germinação e crescimento de plântulas de rúcula cultivada (Eruca sativa $\mathbf{L}$.)
}

Corymbia citriodora extract on germination and growth of cultivated rocket (Eruca sativa L.) seedlings

Extracto de Corymbia citriodora sobre la germinación y crecimiento de plántulas de rúcula cultivada (Eruca sativa L.)

\section{Resumo}

Este trabalho tem como objetivo avaliar os possíveis efeitos alelopáticos do extrato aquoso de eucalipto (Corymbia citriodora) em diferentes concentrações $(0,25,50,75$ e $100 \%)$ na germinação das sementes, crescimento inicial e no desenvolvimento de mudas de rúcula (Eruca sativa L.). Utilizou-se Delineamento Inteiramente Casualizado, com três repetições e cinco tratamentos compostos por doses crescentes $(0,25,50,75$ e $100 \%)$ de extrato de eucalipto testados tanto em mudas, por aplicação foliar, quanto em sementes, por embebição. O extrato foi produzido pelo método frio de turbólise, com folhas de eucalipto trituradas com água em um liquidificador. Para as sementes de rúcula, foi avaliado o Índice de Velocidade de Germinação (IVG) e porcentagem de germinação até os 10 dias após semeadura (DAS) e altura de planta (AP) e número de folhas (NF), comprimento de raiz (CR), relação alométrica (RA). Para as mudas de rúcula, foram avaliadas as variáveis AP, NF, CR, RA, massa fresca da parte aérea (MFPA), massa fresca da raiz (MFRZ), massa seca da parte aérea (MSPA) e massa seca da raiz (MSRZ). A análise estatística dos dados foi realizada com o auxílio do aplicativo computacional SISVAR. Os resultados das variáveis estudadas foram submetidos à análise de variância e Teste de Tukey a 5\% de probabilidade e à análise de regressão, para as variáveis quantitativas, quando o resultado da ANAVA foi significativo. Diante dos resultados obtidos, concluiu-se que extrato aquoso de eucalipto não apresentou efeito negativo sobre a germinação e desenvolvimento de plantas de rúcula.

Palavras-chave: Alelopatia; Extrato aquoso; Eucalipto.

\begin{abstract}
The objective of this presente research is evaluate possible allelopathic effects of aqueous extract of eucalyptus (Corymbia citriodora) at different concentrations (0, 25, 50, 75 and 100\%) on seed germination, initial growth and development of rocket seedlings (Eruca sativa L.). It was used completely randomized design (DIC), with three replications and five treatments composed of increasing doses $(0,25,50,75$ and 100\%) of eucalyptus extract, tested both in seedlings, by foliar application, and in seeds, by imbibition. The extract was produced by the cold method of turbolysis, with eucalyptus leaves crushed with water in a blender. For rocket seeds, the Germination Speed Index (IVG) and germination percentage up to 10 days after sowing (DAS) and plant height (AP) and number of leaves (NF), root length (CR) were evaluated, allometric ratio (RA). For the rocket seedlings, the variables AP, NF, CR, RA, aerial part fresh mass (MFPA), root fresh mass (MFRZ), aerial part dry mass (MSPA) and root dry mass (MSRZ)
\end{abstract}


were evaluated. Statistical analysis of data was performed with the aid of the computer application SISVAR. The results of the studied variables were submitted to analysis of variance and Tukey's test at 5\% probability and to regression analysis for quantitative variables, when the result of ANAVA was significant. Based on the results obtained, it was concluded that the aqueous extract of eucalyptus had no negative effect on the germination and development of rocket plants.

Keywords: Allelopathy; Aqueous extract; Eucalyptus.

\section{Resumen}

Este trabajo tiene como objetivo evaluar los posibles efectos alelopáticos del extracto acuoso de eucalipto (Corymbia citriodora) a diferentes concentraciones $(0,25,50,75$ y 100\%) sobre la germinación de semillas, crecimiento inicial y desarrollo de plántulas de rúcula (Eruca sativa L.). Se utilizó un diseño completamente al azar, con tres repeticiones y cinco tratamientos compuestos por dosis crecientes $(0,25,50,75$ y $100 \%)$ de extracto de eucalipto, testeado tanto en plántulas, por aplicación foliar, como en semillas, por imbibición. El extracto fue elaborado por el método de turbolisis en frío, con hojas de eucalipto trituradas con agua en una licuadora. Para las semillas de rúcula, se evaluó el Índice de Velocidad de Germinación (IVG) y el porcentaje de germinación hasta 10 días después de la siembra (DAS) y la altura de la planta (AP) y el número de hojas (NF), longitud de la raíz (CR), relación alometrica (RA). Para las plántulas de rúcula se evaluaron las variables AP, NF, CR, RA, masa fresca de la parte aérea (MFPA), masa fresca de la raíz (MFRZ), masa seca de la parte aérea (MSPA) y masa seca de la raíz (MSRZ). El análisis estadístico de los datos se realizó con la ayuda de la aplicación informática SISVAR. Los resultados de las variables estudiadas se sometieron a análisis de varianza y prueba de Tukey al 5\% de probabilidad y al análisis de regresión para variables cuantitativas, cuando el resultado de ANAVA fue significativo. Con base en los resultados obtenidos, se concluyó que el extracto acuoso de eucalipto no tuvo efecto negativo sobre la germinación y desarrollo de las plantas de rúcula.

Palabras clave: Alelopatía; Extracto acuoso; Eucalipto.

\section{Introdução}

O consumo da rúcula (Eruca sativa L.) tem mostrado um crescimento acentuado nas últimas décadas. No Brasil, é uma das folhosas mais consumidas e detém um grande cultivo (Rossi et al., 2004). De acordo com a Companhia de Entrepostos e Armazéns Gerais de São Paulo (CEAGESP) em 2016 foram comercializadas cerca de 4.165 toneladas de rúcula (CEAGESP, 2017). Esse crescimento no consumo pode ser fundamentado em seu considerável valor nutricional (Santos et al., 2020); possui alto teor de ferro, além de quantidades significativas de cálcio e vitaminas (CEAGESP, 2017).

Trabalhos científicos envolvendo sementes de rúcula são escassos tanto no Brasil como no exterior (Steiner et al., 2010). A alta qualidade de sementes de hortaliças é de suma importância, principalmente quanto à germinação uniforme, necessária para garantir um estande ideal de plantas.

Com o crescimento do consumo e produção desta hortaliça, é necessário que haja uma multidisciplinaridade de ações que procurem combater vetores do insucesso da produção: insetos vetores de patógenos (Gonçalves \& Costa, 2018), doenças como a ferrugem-branca (Liberalli, 2014) e a fusariose (Nascimento, Almeida, \& Nunes 2020), além da ocorrência de plantas daninhas. As técnicas voltadas ao manejo fitossanitário utilizadas pela agricultura convencional para solução dos problemas enfrentados pelo cultivo da rúcula atualmente, geram cada vez mais danos ambientais. A utilização de extratos ou óleos vegetais atuam como opções de controle ecológico.

Determinadas plantas possuem um mecanismo conhecido como alelopatia, que é baseado na síntese de metabólitos secundários, que têm a capacidade de interferir no ciclo de vida de outras plantas. Tais alelopáticos podem ter influência sobre a germinação de sementes e desenvolvimento de plântulas, absorção de água e nutrientes, crescimento de raízes, potencial fotossintético e até mesmo no controle de pragas e doenças (Mattos, Machado, Rissato, \& Alves, 2020).

Diversas plantas são citadas como causantes de alelopatia. Souza, Stein, Cattelan, Bobrowski e Rocha (2005), constataram o efeito alelopático e citotóxico de extratos de capim-cidreira (Cymbopogon citratus) e estévia (Stevia rebaudiana) sobre sementes de alface e rúcula. Alves, Oliveira, França, Alves e Pereira (2011) encontraram potencial alelopático em plantas medicinais e Cremonez, Cremonez, Camargo e Feiden (2013) em plantas encontradas em sistemas agrícolas no Brasil. O eucalipto é encontrado na literatura como uma das principais espécies produtoras de substâncias 
alelopáticas.

Nativas da Austrália, as plantas do gênero Eucalyptus são caracterizadas por sintetizarem aleloquímicos. Nessas árvores, a maior quantidade desses compostos químicos é encontrada nas folhas e em menores concentrações no caule (Pereira, Costa, \& Borém, 2005). Os efeitos alelopáticos mais acentuados sob a germinação de sementes são observados em extratos foliares de eucalipto (EFE) mais concentrados (Pereira et al., 2005).

De acordo com Goetze e Thomé (2004), o extrato de Eucalyptus grandis apresenta efeito inibitório significativo na germinação de sementes de brócolis, alface e repolho; assim como o extrato do Corymbia citriodora, que reduziu a velocidade de germinação de plantas de alface e picão-preto (Ferreira, Souza, \& Faria, 2007; Pressinate, 2017).

Apesar da importância econômica da rúcula, existem poucos estudos relacionados à cultura e a utilização alelopática de extratos vegetais (Dijkstra et al., 2017). A partir disto, o presente estudo teve como propósito avaliar os possíveis efeitos alelopáticos do extrato aquoso de eucalipto $C$. citriodora em diferentes concentrações $(0,25,50,75$ e $100 \%)$ na germinação das sementes, crescimento inicial e no desenvolvimento de mudas de rúcula (Eruca sativa L.).

\section{Metodologia}

O experimento foi realizado no município de Ilha Solteira $\left(20^{\circ} 25^{\prime} 58^{\prime \prime} \mathrm{S} 51^{\circ} 20^{\prime} 34^{\prime \prime} \mathrm{O}\right)$ e, segundo a classificação de Köppen e Geiger o clima é Aw, com temperaturas, de acordo com o histórico mensal, variando de 17 a $31^{\circ} \mathrm{C}$ e pluviosidade média anual de $1.255,8 \mathrm{~mm}$.

O delineamento estatístico utilizado foi o Delineamento Inteiramente Casualizado (DIC), com três repetições e cinco tratamentos compostos por doses crescentes $(0,25,50,75$ e 100\%) de extrato de eucalipto C. citriodora - EAE, testados tanto em mudas, por aplicação foliar, quanto em sementes, por embebição.

Para a produção do EAE, o método utilizado foi a frio de turbólise, com folhas de $C$. citriodora trituradas com água em um liquidificador, numa proporção de 10:100, respectivamente. A solução foi filtrada primeiramente com auxílio de uma peneira, e posteriormente, com auxílio de um filtro de papel, obtendo-se então o EAE correspondente à concentração de $100 \%$. A partir disto, para se obter as demais concentrações (25, 50 e 75 e 100\%) foi retirado uma alíquota da solução concentrada 5, 25, 45 e $65 \mathrm{~mL}$ respectivamente, completando com água até obter $100 \mathrm{~mL}$ de solução.

As sementes de rúcula, variedade cultivada, foram embebidas por quinze minutos no EAE de acordo com os respectivos tratamentos. Após o período de embebição, foram semeadas em três bandejas descartáveis de duzentas células, semeando-se três sementes por cova para garantia de germinação a uma profundidade de aproximadamente $0,5 \mathrm{~cm}$ e identificados com fitas, utilizando substrato comercial (Tabela 1) e logo após a germinação foi realizado o desbaste deixando apenas uma planta por célula.

Tabela 1. Características do substrato Tropistrato HD Hortaliças®.

\begin{tabular}{|c|c|c|c|c|c|c|c|}
\hline \multirow{3}{*}{$\begin{array}{l}\text { Umidade* }^{*} \\
(\% \mathbf{p} / \mathbf{p})\end{array}$} & \multirow{3}{*}{$\begin{array}{l}\text { CRA* } \\
(\% \mathbf{p} / \mathbf{p})\end{array}$} & \multirow{3}{*}{$\begin{array}{c}\text { Densidade* } \\
\text { base seca } \\
\text { kg/m }\end{array}$} & \multirow{3}{*}{$\begin{array}{c}\text { Densidade* } \\
\text { base úmida } \\
\qquad \mathrm{kg} / \mathrm{m}^{3}\end{array}$} & \multirow{2}{*}{\multicolumn{2}{|c|}{$\begin{array}{c}\text { pH } \\
\begin{array}{c}\text { Propagação água: } \\
\text { substrato }\end{array} \\
\end{array}$}} & \multicolumn{2}{|c|}{$\mathrm{CE}(\mathrm{mS} / \mathrm{cm})$} \\
\hline & & & & & & \multicolumn{2}{|c|}{ Propagação água: substrato } \\
\hline & & & & $1,5: 1$ & $5: 1 *$ & $1,5: 1$ & $5: 1 *$ \\
\hline 60 & 130 & 200 & 500 & $5,8( \pm) 0,3$ & $5,8( \pm) 0,4$ & $2,0( \pm) 0,3$ & $5,0( \pm) 0,3$ \\
\hline
\end{tabular}

CRA = Capacidade de retenção de água; CE = Condutividade elétrica; *Métodos de estabelecidos pela IN 17/07 (MAPA). Fonte: Autores.

As mudas de rúcula foram adquiridas comercialmente - com 21 dias de germinação, e replantadas em sacos plásticos 
próprios para mudas, de $15 \mathrm{~cm}$ x $15 \mathrm{~cm}$, utilizando também substrato comercial. A aplicação dos tratamentos foi realizada após 7 DAR até 14 DAR.

Para as sementes, foi avaliado o Índice de Velocidade de Germinação (IVG) segundo Maguire (1962) (Eq. 1), realizando-se análises diárias até 7 dias após semeadura (DAS) e porcentagem de germinação (Eq. 2). A partir do 10 DAS, foi avaliado o crescimento vegetativo inicial, avaliando altura de planta (AP), número de folhas (NF), comprimento de raiz (CR), relação alométrica (RA) aos 15, 20 e 25 DAS.

$$
I V G=\sum n i / i \quad(\text { Eq. 1) }
$$

Onde: ni = número de sementes germinadas por dia; i = número de dias transcorridos a partir da semeadura.

$$
\% \text { germinação }=\frac{\text { número de semente germinada }}{n^{2} \text { total de sementes }} \times 100 \quad \text { (Eq. 2) }
$$

Para as mudas, foram realizadas avaliações aos 7, 10, 15, 20, 25 e 30 DAR, sendo três plantas por parcela, por avaliação. Aos 7, 10, 15, 20 e 25 DAR foram realizadas avaliações das variáveis altura de planta (AP) e número de folhas (NF). Aos 30 DAR, foram escolhidas plantas com melhor desenvolvimento de cada parcela e realizada avaliações das variáveis AR, NF, comprimento de raiz (CR), relação alométrica (RA), massa fresca da parte aérea (MFPA), massa fresca da raiz (MFRZ), massa seca da parte aérea (MSPA) e massa seca da raiz (MSRZ).

A análise estatística dos dados foi realizada com o auxílio do aplicativo computacional SISVAR. Os resultados das variáveis estudadas foram submetidos à análise de variância e Teste de Tukey a 5\% de probabilidade e à análise de regressão, para as variáveis quantitativas, quando o resultado da ANAVA foi significativo.

\section{Resultados e Discussão}

A porcentagem de germinação das sementes foi de 100\%, sendo que, ao 4 DAS, todas as sementes já haviam germinado. Após a análise de variância das sementes (Tabela 2), observou-se que as doses de cada tratamento, não influenciaram significativamente no IVG, bem como a porcentagem de germinação.

Tabela 2. Análise de variância para Índice de Velocidade de Germinação (IVG) e porcentagem de germinação (\% germ.) para sementes tratadas com extrato de Corymbia citriodora.

\begin{tabular}{ccccc}
\hline VARIÁVEL & GL & $\begin{array}{c}\text { FV } \\
\text { DOSES } \\
\text { p-valor }\end{array}$ & Média Geral & CV(\%) \\
\hline IVG & 4 & $0,2000^{\mathrm{ns}}$ & 62,71 & 4,88 \\
\% germ. & 4 & $0,6554^{\mathrm{ns}}$ & 99,16 & 1,30 \\
\hline
\end{tabular}

Fonte: Autores (2021).

Ferreira e Aquila (2000) explicam que o processo de germinação é menos sensível a esses compostos do que outros processos, como o desenvolvimento radicular e aéreo. Bedin, Mendes, Trecente e Silva (2006), avaliaram a influência do extrato aquoso de E. citriodora nas concentrações de 1\%, 3\% e 5\% na germinação de sementes de tomate e não obtiveram interferência na germinação da hortaliça.

Segundo Ferreira et al. (2013), o extrato aquoso do E. citriodora nas concentrações de $75 \%$, 50\% e $25 \%$ não interferem no IVG nem na porcentagem de germinação de plantas de alface. Em contrapartida, Souza e Cardoso (2012), concluíram que o extrato aquoso de Eucaliptus grandis, obtido pelo método a frio de turbólise, em concentrações de 50, 75 e 
$100 \%$ inibiu sim a germinação de sementes de alface. O mesmo relata Pressinate (2017) que observou que extratos aquosos de C. citriodora também inibem totalmente a germinação de alface e picão-preto nas concentrações de 50, 75 e $100 \%$.

O presente trabalho evidenciou que o uso do extrato de eucalipto não afeta o crescimento inicial de sementes de rúcula, bem como a altura das plântulas e a relação alométrica (Tabela 3).

Tabela 3. Análise de variância para altura de plantas (AP) e relação alométrica (RA) para plântulas de sementes tratadas com extrato de Corymbia citriodora.

\begin{tabular}{|c|c|c|c|c|c|}
\hline \multirow[b]{2}{*}{ VARIÁVEIS } & \multicolumn{3}{|c|}{ FONTES DE VARIAÇÃO } & \multirow[b]{2}{*}{ Média Geral } & \multirow[b]{2}{*}{$\mathrm{CV}(\%)$} \\
\hline & DOSE & $\begin{array}{l}\text { DAR } \\
\text { p-valo }\end{array}$ & DAR x DOSE & & \\
\hline $\mathbf{A P}$ & $0,7546^{\mathrm{ns}}$ & $0,0381^{*}$ & $0,5943^{\mathrm{ns}}$ & 2,4 & 19,11 \\
\hline \multirow[t]{3}{*}{$\mathbf{R A}$} & $0,4664^{\mathrm{ns}}$ & $0,4050^{\mathrm{ns}}$ & $0,3456^{\mathrm{ns}}$ & 0,42 & 133,61 \\
\hline & \multicolumn{5}{|c|}{ Médias DOSE } \\
\hline & $\mathbf{0}$ & 25 & 50 & 75 & 100 \\
\hline AP & 2,474 & 2,3814 & 2,3259 & 2,4 & 2,4629 \\
\hline \multirow[t]{3}{*}{$\mathbf{R A}$} & 0,3992 & 0,44055 & 0,36 & 0,3581 & 0,61 \\
\hline & \multicolumn{5}{|c|}{ Médias DAS } \\
\hline & & 15 & 20 & 25 & \\
\hline $\mathbf{A P}$ & & 2,3111 & 2,5177 & 2,3977 & \\
\hline $\mathbf{R A}$ & & 0,5217 & 0,3948 & 0,3633 & \\
\hline
\end{tabular}

Fonte: Autores (2021).

Os resultados de Yamagushi, Gusman e Vestena (2011), relatam a interferência negativa do extrato de eucalipto no crescimento inicial de plântulas de espécies cultivadas e o mesmo efeito sob o alongamento e estrutura celular, síntese de hormônios responsáveis pelo crescimento, fotossíntese, respiração e desenvolvimento do sistema radicular, por apresentar menor comprimento, raízes atrofiadas e defeituosas.

O mesmo comportamento foi verificado na aplicação do extrato nas mudas. Nota-se pela análise de variância (Tabela 4) e pelos valores médios de cada dose (Tabela 5) para as variáveis número de folhas (NF) e altura da planta (AP) das mudas de rúcula regadas com EAE que as doses de extrato não interferiram de modo significativo nas variáveis estudadas.

Foi observada diferença significativa apenas para o fator Dias Após Replantio (DAR), conforme esperado e, não sendo encontrada diferença para a interação do fator dose e DAR, evidenciando que nenhum dos tratamentos obteve um resultado positivo - ou negativo, que difira dos outros.

Subscrevendo Ferraz et al. (2012), que não observaram alteração significativa da variável altura de plantas em mudas de cebola em diferentes concentrações de Corymbia citriodora, Espinosa (2019) em um estudo sobre atividade alelopática de extrato aquoso de Eucalyptus grandis Hill ex Maiden sobre alface e picão-preto observaram que o extrato do eucalipto também não teve alteração sobre a altura das plantas avaliadas.

Tabela 4. Análise de variância para altura de plantas (AP) e número de folhas (NF) para mudas tratadas com extrato de Corymbia citriodora.

VARIÁVEIS FONTES DE VARIAÇÃO




\begin{tabular}{|c|c|c|c|c|c|c|}
\hline & \multicolumn{2}{|c|}{ DOSE } & DAR & DAR x DOSE & Média Geral & $\mathrm{CV}(\%)$ \\
\hline \multicolumn{7}{|c|}{ p-valor } \\
\hline NF & \multicolumn{2}{|c|}{$0,1047^{\mathrm{ns}}$} & $0,0000^{* *}$ & $0,4352^{\mathrm{ns}}$ & 75,71 & 12,14 \\
\hline \multirow[t]{3}{*}{$\mathbf{A P}$} & \multicolumn{2}{|c|}{$0,9995^{\mathrm{ns}}$} & $0,0000^{* *}$ & $0,9061^{\mathrm{ns}}$ & 9,65 & 11,83 \\
\hline & \multicolumn{6}{|c|}{ Médias DOSE } \\
\hline & \multicolumn{2}{|c|}{$\mathbf{0}$} & 25 & 50 & 75 & 100 \\
\hline $\mathbf{N F}$ & \multicolumn{2}{|c|}{77,09} & 71,76 & 16,74 & 80,24 & 72,74 \\
\hline \multirow[t]{3}{*}{$\mathbf{A P}$} & \multicolumn{2}{|c|}{9,63} & 9,62 & 9,68 & 9,68 & 9,68 \\
\hline & \multicolumn{6}{|c|}{ Médias DAR } \\
\hline & $\mathbf{0}$ & 7 & 15 & 20 & 25 & 30 \\
\hline $\mathbf{N F}$ & 61,5106 & 80,0773 & 90,2226 & 85,5553 & 74,5766 & 61,4446 \\
\hline $\mathbf{A P}$ & 5,9973 & 8,544 & 100.706 & 11,0993 & 11,116 & 11,1193 \\
\hline
\end{tabular}

Fonte: Autores (2021).

$\mathrm{Na}$ Tabela 5 foi apresentada a análise de variância para crescimento da raiz (CR), relação alométrica (RA), massa fresca da raiz (MFRZ), massa fresca da parte aérea (MFPA), massa seca da raiz (MSRZ) e massa seca da parte aérea (MSPA), onde, também não houve diferença significativa entre as doses utilizadas de EAE. O mesmo foi observado por Aleixo, Nascimento e Barroso (2016), que não notaram mudança no crescimento radicular de alface tratado com extrato de folhas e serapilheira de C. citriodora e por Oliveira, Alves, Teixeira, Silva e Bonfim (2018) que não constataram diferença significativa para MFRZ, MFPA, MSRZ e MSPA estudando o efeito alelopático do capim-cidreira (Cymbopogon citratus) na germinação e vigor de sementes de rúcula.

Tabela 5. Análise de variância para crescimento da raiz (CR), relação alométrica (RA), massa fresca da raiz (MFRZ), massa fresca da parte aérea (MFPA), massa seca da raiz (MSRZ) e massa seca da parte aérea (MSPA) para mudas tratadas com extrato de Corymbia citriodora.

\begin{tabular}{|c|c|c|c|c|c|c|}
\hline & CR & RA & MFRZ & MFPA & MSRZ & MSPA \\
\hline FONTES DE VARIAÇÃO & \multicolumn{6}{|c|}{ p-valor } \\
\hline DOSE & $0,7741^{\mathrm{ns}}$ & $0,4611^{\mathrm{ns}}$ & $0,3236^{\mathrm{ns}}$ & $0,2574^{\mathrm{ns}}$ & $0,2125^{\mathrm{ns}}$ & $0,5500^{\mathrm{ns}}$ \\
\hline Média Geral & 15,3206 & 0,8286 & 0,5926 & 4,4100 & 0,0406 & 0,3880 \\
\hline $\mathrm{CV}(\%)$ & 30,55 & 26,27 & 21,62 & 6,74 & 59,22 & 13,18 \\
\hline DOSE & \multicolumn{6}{|c|}{ Médias } \\
\hline $\mathbf{0}$ & 16,4466 & 0,8633 & 0,6000 & 4,5366 & 0,0566 & 0,3666 \\
\hline 25 & 17,1766 & 0,7066 & 0,5266 & 4,1933 & 0,0333 & 0,4100 \\
\hline 50 & 15,6333 & 0,7300 & 0,5233 & 4,1666 & 0,0300 & 0,6533 \\
\hline 75 & 12,5000 & 1,0233 & 0,5800 & 4,6333 & 0,0200 & 0,4100 \\
\hline 100 & 14,8466 & 0,8200 & 0,7333 & 4,5200 & 0,0633 & 0,4000 \\
\hline
\end{tabular}

Fonte: Autores (2021).

Foi observado que, para a massa fresca da raiz (MFRZ) e massa seca da raiz (MSRZ) (Figura 1-A), a concentração de $100 \%$ obteve a maior média comparadas às outras concentrações do EAE, já para a massa fresca da parte aérea (MFPA) e massa seca da parte aérea (MSPA) (Figura1-B), as maiores médias foram nas concentrações de $75 \%$ e $50 \%$, respectivamente. Espinosa (2019) observou um aumento de 370,8 \% da biomassa fresca da alface e de 334,6\% da biomassa seca, sendo indicado pelo aumento do diâmetro das raízes e caulículo, quando utilizou o extrato aquoso de E. grandis Hill ex Maiden, na concentração de $25 \%$. 
Figura 1. (A) Médias de massa fresca da raiz (MFRZ) e massa seca da raiz (MSRZ) nas concentrações de 0\%, 25\%, 50\%, $75 \%$ e $100 \%$ do EAE. (B) Médias de massa fresca da parte aérea e (MFPA), massa seca da parte aérea (MSPA) nas concentrações de $0 \%, 25 \%, 50 \%, 75 \%$ e $100 \%$ do EAE.

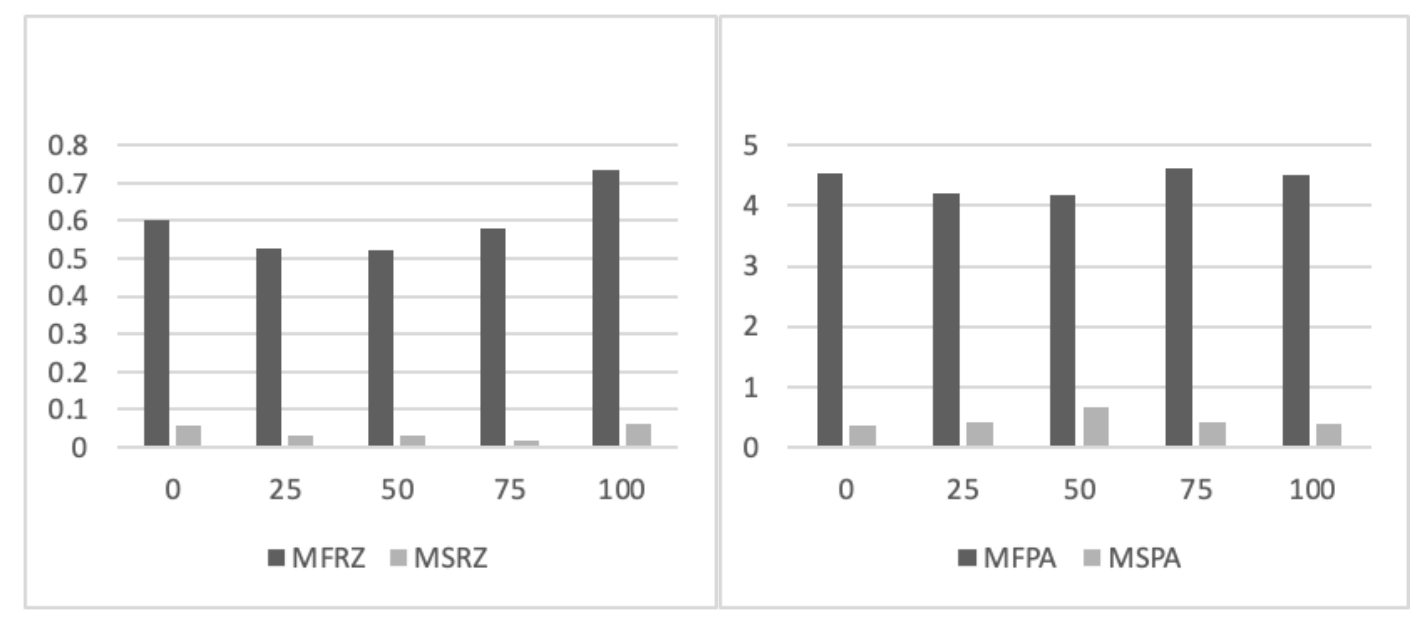

Fonte: Autores (2021).

Os resultados encontrados no experimento mostram que o extrato aquoso de eucalipto (C. citriodora), nas doses utilizadas, não apresentou efeito negativo sobre a germinação e desenvolvimento de plantas de rúcula.

Zeni et al., (2004) testando a eficácia de extratos aquosos e óleos essenciais de eucaliptos como inibidor do desenvolvimento de Botrytis cinerea, Cylindrocladium spathulatum e Rhizoctonia sp., in vitro, obtiveram efeito inibitório sobre esses fungos, tanto do óleo essencial como do extrato aquoso de C. citriodora. Silva et al. (2012) que observaram que o óleo essencial de $C$. citriodora pode ser utilizado como controle para podridão mole em alface crespa. É possível então, que o extrato aquoso de $C$. citriodora seja uma alternativa para controle biológico de doenças em rúcula, posto que as concentrações estudadas do extrato aquoso de eucalipto (C. citriodora) no presente trabalho não apresentaram efeitos negativos sobre a germinação e desenvolvimento de plantas de rúcula.

\section{Conclusão}

Os resultados encontrados no experimento mostram que o extrato aquoso de eucalipto (C. citriodora) pode ser usado para o controle de pragas pois não apresenta efeito negativo sobre a germinação e desenvolvimento de plantas de rúcula.

\section{Referências}

Aleixo, S., Nascimento, M. T., \& Barroso, D. G. (2016). Potencial alelopático de Corymbia citriodora (Hook.) K. D. Hill \& L. A. S. Johnson sobre o estabelecimento de plântulas de espécies arbóreas de Mata Atlântica. Iheringia Série Botânica, 71(3), 277-282.

Alves, L. L., Oliveira, P. V. A., França, S. C., Alves, P. L. C., \& Pereira, P. S. (2011). Atividade alelopática de extratos aquosos de plantas medicinais na germinação de Lactuca sativa L. e Bidens pilosa L. Revista Brasileira de Plantas Medicinais, 13(3), 328-336.

Azevedo, V. K., Braga, T. V. S., \& Goi, S. R. (2007, setembro). Efeito alelopático de extrato de Eucalyptus citriodora e Pinus eliotti sobre a germinação de Lactuca sativa L. (alface). Anais do VIII Congresso de Ecologia do Brasil. Caxambú, MG, Brasil.

Bedin, C., Mendes, L. B., Trecente, V. C., \& Silva, J. M. S. (2006). Efeito alelopático de extrato de Eucalyptus citriodora na germinação de sementes de tomate (Lycopersicum esculentum M.). Revista Científica Eletrônica de Agronomia, 5(10).

CEAGESP (2016). Produtos: Rúcula. http://www.ceagesp.gov.br/comunicacao/noticias/conheca-os-beneficios-da-rucula-o-produto-de-destaque-da-semana/.

Cremonez, F. E., Cremonez, P. A., Camargo, M. P., \& Feiden, A. (2013). Principais plantas com potencial alelopático encontradas nos sistemas agrícolas brasileiros. Acta Iguazu, 2(5), 70-88. 
Dijkstra, D. D., Longo, U., Guilherme, I. H., Ferreira, R. V., Dias, L. N. S., \& Buso, W. H. D. (2017). Cultivo de Eruca sativa sob diferentes manejos nutricionais. Revista Agrarian, 35(10), 61-69.

Espinosa, R. Z. Atividade alelopática de extrato aquoso de Eucalyptus grandis Hill ex Maiden sobre alface (Lactuca sativa L.) e picao-preto (Bidens pilosa L.) (2019). Revista Valore, 4(1), 1-14

Ferraz A. P. F., Pinto M. A. D. S. C., Coelho J. L. F., Teles E. C. P. V. A., Calado T. B., \& Sobreira A. M. (2012). Efeito do extrato aquoso de folhas de eucalipto (Corymbia citriodora (Hook.) K.D.Hill \& L.A.S. Johnson) na germinação e no crescimento inicial de cebola. Horticultura. Brasileira, 30(2), 57715779 .

Ferreira, A. G., \& Aquila, M. E. A. (2000). Alelopatia: uma área emergente da ecofisiologia. Revista Brasileira de Fisiologia Vegetal, 12(1), 175-204.

Ferreira, D. A. T., Silva, M. S. A., Monteiro, E. C., Duarte, J. A. S., Silva, L. D., \& Cabanez, P. A. (2013). Efeito alelopático do extrato aquoso de Eucalyptus citriodora na germinação de sementes de Lactuca sativa. Anais do I Seminário de biodiversidade e agroecossistemas amazônicos, Alta Floresta, MT, Brasil.

Ferreira, M. C., Souza, J. R. P., \& Faria, T. J. (2007). Potenciação alelopática de extratos vegetais na germinação e no crescimento inicial de picão-preto e alface. Ciênc. Agrotec. 3(4), 1054-1060.

Fonseca, M. C. M., Lehner, M. S., Gonçalves, M. G., Paula Júnior, T. J., Silva, A. F., Bonfim, F. P. G., \& Prado, A. L. (2015).Potential of essential oils from medicinal plants to control plant pathogens. Revista brasileira de plantas medicinais, 17(1), 45-50.

Goetze, M., \& Thomé, G. C. H. (2004). Efeito alelopático de extratos de Nicotiana tabacum e Eucalyptus grandis sobre a germinação de três espécies de hortaliças. R. Bras. Agrociência, 10(1), 43-50.

Gonçalves, N. G. G., \& Costa, E. C. (2018) Bioatividade do nim sobre Myzus persicae (Sulzer, 1776) (hemiptera: aphididae) em Eruca sativa Miller. Anais do Congresso Técnico Científico Da Engenharia e Da Agronomia, 2018, Maceió, AL, Brasil.

Liberalli, L. (2014). Controle alternativo da ferrugem-branca da rúcula pelo extrato aquoso de plantas medicinais. TCC (Graduação) - Curso de Agronomia, Universidade Federal da Fronteira Sul, Laranjeiras do Sul, PR, Brasil.

Mattos, A. P., Machado, B. R., Rissato, B. B., \& Alves, L. H. B. (2020). Extrato de babosa e manjericão na germinação e crescimento inicial de rúcula. Revista Verde, 15(1), 100-104.

Nascimento, I., Almeida, I. Z., \& Nunes, S. E. A. (2020). Potencial do extrato de tiririca, Cyperus rotundus L., no desempenho produtivo e controle de fusariose em rúcula. Revista Eletrônica Científica Ensino Interdisciplinar, 6(19), 120-127.

Oliveira, S. G., Alves, L. F., Teixeira, D. A., Silva, H. E. R., \& Bonfim, F. P. G. (2018) Efeito alelopático do capim cidreira sobre a germinação e desenvolvimento de mudas de rúcula. Revista Mirante, 11(7), 1-2.

Pereira, G. C, Costa, A. S. V., \& Borém, R. A. T. (2005). Efeitos de extratos aquosos de Eucalyptus Grandis na germinação de sementes de três culturas agrícolas. Anais do VII Congresso de Ecologia Brasileira, Caxambú, MG, Brasil.

Pressinatte, F. A. (2017). Análise dos efeitos alelopáticos de extrato de eucalipto (Corymbia citriodora) sobre a germinação de alface (Lactuca sativa L.) E de plantas daninhas infestantes em horticultura. TCC (Graduação) - Curso de Agronomia, Unicesumar, Maringá, PR, Brasil.

Razavi, S. M. (2011). Plant coumarins as allelopathic agents. International Journal Of Biological Chemestry, 1(5), 86-90.

Rossi, F., Fabri, E. G., Sala, F. C., Rondino, E., Minami, K., Melo, P. C. T. de, \& Costa, C. P. da. (2004). Caracterização varietal de rúcula (Eruca sativa) cultivada. Horticultura Brasileira. Brasília.

Santos, A. Y. O., Júnior, D. N. S., Freire, M. M., Neto, J. V. E., Morais, E. G., \& Silva, G. G. C. (2020). Desenvolvimento radicular da rúcula a doses crescentes de carvão vegetal e manipueira. Brazilian Journal Of Animal And Environmental Research, 3(3), 1085-1095.

Silva, C. L., Souza, E. B., Felix K. C. S., Santos, A. M. G., Silva M. V., \& Mariano R. L. R. (2012). Óleos essenciais e extratos vegetais no controle da podridão mole em alface crespa. Horticultura Brasileira, 30(4), 632-638.

Souza, S. A. M., Stein, V. C., Cattelan, L. V., Bobrowski, V. L., \& Rocha, B. H. G. (2005). Utilização de sementes de alface e de rúcula como ensaios biológicos para avaliação do efeito citotóxico e alelopático de extratos aquosos de plantas medicinais. Revista de Biologia e Ciências da Terra, 5(1).

Souza, V. M., \& Cardoso, S. B. (2012). Efeito alelopático do extrato de folhas de Eucalyptus grandis sobre a germinação de Lactuca sativa L. (alface) e Phaseolus vulgaris L(feijão). Revista Eletrônica de Educação e Ciência, 2(3), 1-1.

Steiner, F., Pinto, A. S., Freiberger, M. B., Zoz, T., Dranski, J. A., Rheinheimer, A. R., Echer, M. M., \& Guimarães, V. F. (2010). Germinação de sementes de rúcula sob diferentes temperaturas. Scientia Agraria, 11(2), 119-124.

Tirani, P. E., Fornasier, J. B., \& Lisbão, R. S. (1992). Cultura da rúcula. Campinas: IAC. 8p. (Boletim técnico 146).

Zeni, T. L., Júnior, A. G., Auer, C. G., Magalhães, W. L. E., Duarte, J. A. S. \& Bizi, R. M. (2004). Uso de extrato aquoso e óleo de eucaliptos no controle de fungos fitopatogênicos in vitro. Anais do Evento De Iniciação Científica Da Embrapa Florestas, Colombo, PR, Brasil.

Yamagushi, Q. M., Gusman, S. G., \& Vestena, S. (2011). Efeito alelopático de extratos aquosos de Eucalyptus gloulus Labill. E de Casearia sylvestris sw. Sobre espécies cultivadas. Ciências Agrárias, 32(4), 1361-1374. 